\title{
REORGANIZAÇÃO CURRICULAR DA DISCIPLINA DE ESTÁGIO: EM QUESTÃO O PIBID E A RESIDÊNCIA PEDAGÓGICA
}

\author{
Curricular reorganization of the subject internship: in question the pibid and the pedagogical \\ residence
}

Reorganización curricular de la disciplina de estádio: en cuestión el pibid y la residencia pedagógica

\author{
Cristiane Ribeiro Cabral Rocha* \\ Jacira Helena do Valle Pereira Assis ** \\ Sandra Novais Sousa***
}

https://doi.org/10.38117/2675-181X.formov2021.v3i1n5.403-422.

\section{Resumo}

O artigo tem como objetivo analisar às modificações do Programa Institucional de Bolsas de Iniciação à Docência-Pibid e o lançamento do Programa de Residência Pedagógica, ambos voltados para a articulação entre conhecimentos acadêmicos e prática, bem como o debate sobre a reorganização curricular no âmbito das licenciaturas. $\mathrm{O}$ artigo analisa os novos editais e portarias do Ministério da Educação (MEC) e da Coordenação de Aperfeiçoamento de Pessoal de Nível Superior (Capes) e outras pesquisas da área. Os resultados, apontam que as inflexões do Pibid e o lançamento do Programa de Residência pedagógica não atendem às demandas de reestruturação da disciplina de Estágio Supervisionado, pois não superam a visão pautada na racionalidade prática que têm embasado tanto essa disciplina como o novo Programa. Conclui-se que a articulação entre teoria e prática necessita priorizar a formação de acadêmicos que tenham condições de analisar de forma crítica o campo educacional.

Palavras-chave: Currículo; Licenciaturas; Políticas Educacionais; Formação Docente. 


\begin{abstract}
The article aims to analyze the demands established in undergraduate courses regarding the permanence of students in the school space and the relations between praxis. Its object of study is the debate about the curricular reorganization of undergraduate courses in face of the modifications of the Institutional Program of Scholarships for Initiation to Teaching Pibid and the launching of the Pedagogical Residency Program, both aimed at the articulation between academic knowledge and practice in undergraduate courses. The article analyzes the new edicts and ordinances of the Ministry of Education and Capes and other research in the area. The results indicate that the inflections of Pibid and the launching of the Pedagogical Residency Program do not meet the demands of restructuring the discipline of Supervised Internship, because they do not overcome the vision based on the practical rationality that has supported both this discipline and the new Program. We conclude that the articulation between theory and practice needs to prioritize the formation of students who are able to critically analyze the educational field.
\end{abstract}

Keywords: Curriculum; Bachelor's degrees; Educational Policies; Teacher Training.

\title{
Resumen
}

El artículo tiene como objetivo analizar las exigencias que se establecen en los cursos de licenciatura en cuanto a la permanencia de los estudiantes en el espacio escolar y las relaciones entre la praxis. Tiene como objeto de estudio el debate sobre la reorganización curricular de los cursos de pregrado frente a las modificaciones del Programa Institucional de Becas de Iniciación a la Enseñanza - Pibid y la puesta en marcha del Programa de Residencias Pedagógicas, ambos dirigidos a la articulación entre el conocimiento académico y la práctica en los cursos de pregrado. El artículo analiza los nuevos edictos y ordenanzas del Ministerio de Educación y Capes y otras investigaciones en la materia. Los resultados señalan que las inflexiones del Pibid y la puesta en marcha del Programa de Residencias Pedagógicas no responden a las exigencias de reestructuración de la disciplina de las Prácticas Supervisadas, porque no superan la visión basada en la racionalidad práctica que ha fundamentado tanto esta disciplina como el nuevo Programa. Se concluye que la articulación entre la teoría y la práctica necesita priorizar la formación de estudiantes que sean capaces de analizar críticamente el campo educativo.

Palabras clave: Currículo; Grados; Políticas Educativas; Formación docente.

\section{Introdução}

As questões envolvendo a atratividade da carreira do magistério para os jovens concluintes do ensino médio têm mobilizado tanto pesquisadores da área acadêmica quanto gestores do poder público, o que tem gerado, por um lado, relatórios de pesquisas 
Reorganização Curricular da disciplina de Estágio:

Em questão o Pibid e a Residência Pedagógica

científicas e, por outro, o lançamento de políticas públicas voltadas especificamente para os alunos das diferentes licenciaturas.

Entre os relatórios de pesquisas acadêmicas sobre o tema da profissão docente, $\mathrm{o}$ Relatório Final - Atratividade da Carreira Docente no Brasil (GATTI et al., 2009) produzido pela Fundação Vítor Cívita, com base nos resultados de uma pesquisa nacional encomendada à Fundação Carlos Chaves, aponta que apenas $2 \%$ dos concluintes do ensino médio entrevistados indicaram interesse em cursos de licenciatura, enquanto "[...] $83 \%$ optaram, claramente, por carreiras desvinculadas da atividade docente" (GATTI, et al., 2009, p. 42), o que mostra claramente uma rejeição à carreira docente.

Marques (2018, p. 23), ao apresentar os dados de uma pesquisa semelhante, porém em nível local, realizada entre os estudantes do $3^{\circ}$ ano do ensino médio da rede estadual de ensino de Mato Grosso do Sul, afirma que "O Brasil tem formado menos professores a cada ano com a diminuição de ingressantes nos cursos de licenciatura." A autora cita dados do Instituto Nacional de Estudos e Pesquisas Educacionais Anísio Teixeira (Inep) que mostram que "[...] os cursos de Bacharelado acumulam um total de 69\% das matrículas, enquanto as Licenciaturas são responsáveis por 18,9\%. Já os cursos Tecnológicos respondem por 11,8\%.” (MARQUES, 2018, p. 23).

Entre os 7.894 estudantes de 211 escolas de Mato Grosso do Sul que responderam ao questionário composto de 22 questões, sendo 6 questões abertas e 16 questões fechadas, 3,58\% indicaram a pretensão de cursar Pedagogia e apenas 0,17\% outras licenciaturas. Os três cursos com maior porcentagem de indicação de pretensão foram Direito (11,25\%), Engenharias - diversas áreas $(9,90 \%)$ e Medicina $(8,65 \%)$.

Entre as razões para a não escolha de cursos superiores de licenciatura, foram citadas: "não se identificam, não tem vocação ou não gostam dessa profissão" (25\%); "falta de paciência para ensinar" (8,86\%); "desvalorização dessa profissão pela sociedade, principalmente pelos governantes" (5,22\%); "salário ruim/baixo" (5,09\%); "profissão muito estressante, rotina cansativa, cansaço excessivo e carga horária de trabalho extensa" (4,25\%); "preferem outros cursos" (3,85\%); "alunos indisciplinados e desrespeito dos alunos com os professores" (2,90\%); "dificuldade de ensinar pessoas" (1,56\%). (MARQUES, 2018, p. 53).

Como em outras profissões, o magistério necessita constantemente de novos profissionais, haja vista fatores como o aumento populacional, a demanda pela ampliação do acesso à escola, principalmente na educação infantil, que tem o menor índice de cobertura, sobretudo na faixa de 0 a 3 anos, a aposentadoria de professores, entre outros. 
Sendo assim, a baixa procura pelas licenciaturas, aliada à desistência tanto durante o curso de graduação como logo após as primeiras experiências como profissional (ANDRÉ, 2012; GIOVANNI, MARIN, 2014), tem se mostrado um problema relevante no contexto brasileiro.

Uma das ações do Ministério da Educação (MEC) voltadas especificamente para essas problemáticas apontadas foi o lançamento, em 2007, do Programa Institucional de Bolsa de Iniciação à Docência (Pibid), que apresenta, dentre os seus objetivos, o de "[...] valorizar o magistério, incentivando os estudantes que optam pela carreira docente;" (BRASIL, CAPES, 2007a, p. 39).

Recentemente, no entanto, o Pibid sofreu modificações importantes, principalmente a partir de 2017, quando foi lançada uma nova política, o Programa de Residência Pedagógica, que, por ter como proposta o aproveitamento da sua carga horária na disciplina de Estágio Supervisionado, demandará modificações na estrutura curricular das licenciaturas.

Diante dessa breve contextualização, o presente artigo tem como objetivo compreender as demandas estabelecidas nos cursos de licenciatura em relação ao tempo de permanência dos acadêmicos no espaço escolar e as relações entre a teoria e prática. Para tanto, realiza no primeiro tópico uma análise do histórico de implantação do Programa Institucional de Bolsas de Iniciação à Docência (Pibid) e, no segundo tópico, do Programa de Residência Pedagógica. Nas considerações finais, discutem-se, a partir dos dados apresentados, as implicações da implantação do Programa de Residência Pedagógica para o currículo das licenciaturas, especificamente no que se refere à disciplina de Estágio Supervisionado.

Esse estudo utiliza dados produzidos em pesquisas das autoras, concluídas e em andamento, revisitados a partir do diálogo com outras pesquisas acadêmicas da área e do lançamento de novos editais e portarias do Ministério da Educação (MEC) e da Coordenação de Aperfeiçoamento de Pessoal de Nível Superior (Capes).

\section{As inflexões do Programa Institucional de Bolsa de Iniciação à Docência (Pibid)}

O Programa Institucional de Bolsa de Iniciação à Docência (Pibid) foi lançado pelo governo federal em 2007, por meio da Portaria Normativa ${ }^{\circ} 38$, de 12 de dezembro de 2007, tendo como uma de suas metas a elevação para $90 \%$ da taxa de conclusão média 
Reorganização Curricular da disciplina de Estágio:

Em questão o Pibid e a Residência Pedagógica

dos cursos de licenciatura presenciais, em um prazo de cinco anos. (BRASIL, CAPES, 2007a). Foi elaborado conjuntamente pelo Ministério da Educação (MEC), por meio da Secretaria de Educação Superior (SESu), pela Capes, como já mencionado, e pelo Fundo Nacional de Desenvolvimento da Educação (FNDE).

O Pibid, contudo, não é simplesmente um programa de bolsas. É uma proposta de incentivo e valorização do magistério e de aprimoramento do processo de formação de docentes para a educação básica. Os alunos de licenciatura exercem atividades pedagógicas em escolas públicas de educação básica, contribuindo para a integração entre teoria e prática, para a aproximação entre universidades e escolas e para a melhoria de qualidade da educação brasileira. Para assegurar os resultados educacionais, os bolsistas são orientados por coordenadores de área - docentes das licenciaturas - e por supervisores - docentes das escolas públicas onde exercem suas atividades. (GUIMARÃES, 2014, p. 5)

No primeiro edital, lançado em 2007, havia a indicação de que o programa se destinava a "estudantes das instituições federais de educação superior" visando "preparar a formação de docentes em nível superior, em cursos de licenciatura presencial plena, para atuar na educação básica pública." (BRASIL, CAPES, 2007b, p. 1, grifo nosso). A avaliação e aprovação das propostas, restritas às instituições federais de ensino superior e centros federais de educação tecnológica, priorizava o ensino médio e as disciplinas da área de exatas, seguida das disciplinas de Ciências e Matemática da segunda fase do ensino fundamental. Somente de forma complementar outras licenciaturas poderiam ser contempladas, com foco em Letras, Educação Musical e Artística e, em último caso, outras licenciaturas, como, por exemplo, a Pedagogia.

No edital $n^{\circ} 2 / 2009$, as instituições de ensino superior estaduais passaram a ter o direito de submeter projetos. Outro item acrescentado foi a indicação de que os projetos poderiam estar voltados para a "Educação Básica Regular, Educação Especial, Educação de Jovens e Adultos, e a educação básica oferecida nas Comunidades Indígenas, nas Comunidades Quilombolas e no Campo." (BRASIL, CAPES, 2009, p. 4). Outra modificação foi em relação à priorização das áreas, que, no ensino médio, incluiu além daquelas constantes no edital de 2007 (CAPES, 2007b), as licenciaturas de Filosofia, Sociologia; Letras-Português, Pedagogia e as "[...] licenciaturas com denominação especial que atendam a projetos interdisciplinares ou novas formas de organização do ensino médio". (BRASIL, CAPES, 2009, p. 4). 
No Edital nº 011/2012 (BRASIL,CAPES, 2012), a novidade foi a delimitação do número de bolsas, não constante nos editais anteriores. Neste, havia a indicação de que seriam oferecidas 19.000 novas bolsas de iniciação à docência para estudantes de cursos de licenciatura e para coordenadores e supervisores participantes do Pibid, porém não há menção específica de quais licenciaturas seriam priorizadas.

Em 2013, o Edital nº 061 (BRASIL, CAPES, 2013a) aumentou para 72.000 as bolsas a estudantes dos cursos de licenciatura e a professores das Instituições de Ensino Superior e das escolas da rede pública de ensino. Dessas, 10.000 seriam destinadas a acadêmicos de licenciatura do Programa Universidade para Todos (ProUni) e aos professores envolvidos na sua orientação e supervisão. Ainda em 2013, a Portaria no 96, de 18 de julho (BRASIL,CAPES, 2013b), estabeleceu o Regulamento do Programa Institucional de Bolsa de Iniciação à Docência, trazendo regras gerais e tirando o foco das disciplinas Ciência e Matemática, da segunda fase do ensino fundamental, e Física, Química, Biologia e Matemática, do ensino médio, como o era na proposta original.

Nesse mesmo ano, a Capes, por meio de um projeto de pesquisa firmado entre o MEC e a Unesco, “[...] propôs uma avaliação externa do Pibid, mesmo o programa sendo considerado ainda novo." (FUNDAÇÃO CARLOS CHAGAS, 2014, p. 6), coordenada pelos pesquisadores Bernardete Gatti, Marli André, Nelson Gimenes e Laurizete Ferragut.

Nesta pesquisa, realizada pela Fundação Carlos Chagas, foram ouvidos 38.000 bolsistas, entre acadêmicos, coordenadores de IES e professores supervisores, que apontaram aspectos referentes aos fundamentos do programa, "[...] seu desenvolvimento, sua gestão, suas perspectivas e seus impactos e desdobramentos no cotidiano da formação, seja nas instituições formadoras, seja nas escolas públicas onde acontece a prática dos bolsistas de iniciação.” (FUNDAÇÃO CARLOS CHAGAS, 2014, p. 5).

Os resultados, segundo os pesquisadores, foram animadores:

Observou-se como o Pibid é valorizado em todos os níveis, por todos os participantes que responderam aos questionários. Os depoimentos são muito positivos, em sua imensa maioria; os detalhes oferecidos para justificar essa positividade são inúmeros e se expressam nas contribuições descritas. Aprimoramentos devem ser implementados ante o valor atribuído à sua metodologia e às insistentes colocações sobre a necessidade imperativa de sua continuação pelo seu papel de dar valor novo às licenciaturas nas IES, de melhor qualificá-las e a seus docentes, de propiciar melhor 
Reorganização Curricular da disciplina de Estágio:

Em questão o Pibid e a Residência Pedagógica

formação a futuros professores da educação básica, de trazer contribuições aos Professores Supervisores e suas escolas, ao ensino pela criatividade didática. Sem dúvida, pelos dados até aqui analisados, esse é um programa de grande efetividade no que se refere à formação inicial de professores. (FUNDAÇÃO CARLOS CHAGAS, 2014, p. 103).

Em 2014 não houve lançamentos de editais pelo governo federal, apenas no âmbito das diferentes instituições, referentes aos projetos já aprovados e em andamento. Apesar dos investimentos e da avaliação positiva ao final da referida pesquisa encomendada pela própria Capes, a partir de meados de 2015 começaram a surgir rumores de que o programa não teria continuidade ou, ainda, de que haveria modificações em sua estrutura e funcionamento, gerando diversas manifestações de entidades ligadas à educação, pesquisa educação e entre os bolsistas ${ }^{1}$.

O Portal da Agência Brasil divulgou, em 15 de outubro de 2015 a seguinte notícia:

O Programa Institucional de Bolsa de Iniciação à Docência (Pibid) poderá sofrer cortes no próximo ano, segundo a diretora de Formação de Professores da Educação Básica da Coordenação de Aperfeiçoamento de Pessoal de Nível Superior (Capes), ligada ao Ministério da Educação (MEC), Irene Mauricio Cazorla. [...] O programa foi citado no discurso de Mercadante $^{2}$ na cerimônia de transmissão de cargo. Após dizer que é preciso fazer mais com menos, o ministro citou o Pibid como um dos programas que deverá ser revisto. Segundo ele, atualmente o programa tem 86 mil bolsistas. Dos egressos do programa, 18\% tornam-se professores da educação básica. (AGÊNCIA BRASIL, 2015, n.p.).

Alinhado com esse entendimento do Ministério da Educação, foi lançado o Ofício Circular no 2/2016-CGV/DEB/CAPES, de 18 de fevereiro de 2016, o qual trouxe a informação de que "Visando adequar o PIBID à dotação orçamentária disponível para o programa em 2016, [...] as bolsas de iniciação à docência que completam 24 meses não serão prorrogadas" (BRASIL, CAPES, 2016a, p. 1).

Em 2016, o lançamento da Portaria $\mathrm{n}^{\circ}$ 46, de 11 de abril (BRASIL, CAPES, 2016b), revogada dois meses depois, trouxe novo regulamento para o Pibid, que, segundo o Fórum dos Coordenadores Institucionais do Pibid (ForPibid) (2016), deslocava o a 
natureza do Programa do investimento na formação inicial para a execução de trabalhos ligados à reforço escolar, visando a melhoria do Índice de Desenvolvimento da Educação Básica (Ideb). Os licenciandos deveriam atuar, prioritariamente, em “[...] escolas públicas em que o Índice de Desenvolvimento da Educação Básica (Ideb) esteja abaixo da média nacional, de 4,4 [...]”, ou, em alguns casos, “[...] mediante solicitação da IES e aprovação da Capes", seria permitido que "[...] os bolsistas de iniciação à docência atuassem por até dois bimestres em escolas consideradas de excelência." (BRASIL, CAPES, 2016b, p. 5).

Dois meses após a publicação do novo regulamento do Pibid, a Portaria n ${ }^{\circ}$ 46/2016 foi revogada com a publicação da Portaria $n^{\circ}$ 84, de 14 de junho de 2016 (COORDENAÇÃO DE APERFEIÇOAMENTO DE PESSOAL DE NÍVEL SUPERIOR, 2016c). Em sua página oficial, a Capes limitou-se, em 15 de junho de 2016, a emitir a seguinte nota "A Coordenação de Aperfeiçoamento de Pessoal de Nível Superior (Capes) divulgará, posteriormente, orientações e recomendações sobre a continuidade dos projetos Pibid". (BRASIL, CAPES, 2016d, n.p.).

Logo em seguida, a Portaria n n $^{\text {120 }}$, de 22 de julho de 2016 (BRASIL, CAPES, 2016e), indicou que o funcionamento do Pibid continuaria a ser regido pelo Regulamento publicado na Portaria $n^{\circ} 96$ de 18 de julho de 2013.

Desde o seu lançamento e implantação, há uma década, o Pibid vem sofrendo inflexões. Em 18 de outubro de 2017, por exemplo, foi veiculado na página oficial do Ministério de Educação o lançamento de um novo programa, a Residência Pedagógica, sobre o qual teceremos maiores considerações no próximo tópico. Esse programa, segundo o Mec, visava à "modernização" do Pibid:

A Residência Pedagógica faz parte da modernização do Programa Institucional de Bolsas de Iniciação à Docência (Pibid) e traz novidades, como a formação do estudante do curso de graduação, que terá estágio supervisionado, com ingresso a partir do terceiro ano da licenciatura, ao longo do curso, na escola de educação básica. O objetivo principal é a melhoria da qualidade da formação inicial e uma melhor avaliação dos futuros professores, que contarão com acompanhamento periódico. $\mathrm{O}$ programa tem como requisito a parceria com instituições formadoras e convênios com redes públicas de ensino. (BRASIL, MEC, 2017, n.p.).

Assim, em 2018, com a publicação da Portaria Capes $n^{\circ}$ 45, de 12 de março (BRASIL, CAPES, 2018a), o Pibid recebe um novo regulamento. Essa portaria foi alterada pela Portaria ${ }^{\circ} 175$, de 7 de agosto de 2018 que acresce ao novo regulamento 
Reorganização Curricular da disciplina de Estágio:

Em questão o Pibid e a Residência Pedagógica

para a concessão de bolsas a exigência de "formalização de Acordo de Cooperação Técnica (ACT) firmado entre o Governo Federal, por meio da Capes; o Conselho Nacional de Secretários de Educação (Consed) e a União Nacional dos Dirigentes Municipais de Educação (Undime)" (BRASIL, CAPES, 2018b, p. 2), instituindo assim um instrumento para a efetuação do regime de colaboração no Programa de Residência Pedagógica e no Pibid.

Por meio dessa nova regulamentação, poderão se inscrever no Pibid os acadêmicos que estiverem cursando até o $4^{\circ}$ semestre, sendo que os que cursam a partir do $5^{\circ}$ semestre só podem optar pelo Programa de Residência Pedagógica.

Entre as mudanças ocorridas no Pibid com essa nova portaria, há a indicação de que cada subprojeto precisa ter, no mínimo, 24 acadêmicos inscritos para se manter em funcionamento, sendo que, geralmente, é liberada uma bolsa para professor supervisor por subprojeto. Comparativamente, para dimensionar o quanto a mudança foi significativa nesse aspecto, a Portaria 96/2013 informava que os subprojetos deveriam ter o mínimo de 5 bolsistas de iniciação à docência para serem autorizados a funcionar.

Assim, diante das inflexões do Pibid desde o seu lançamento, o próximo tópico traz algumas considerações sobre o Programa de Residência Pedagógica. Como o programa está em início de implantação, essas considerações foram tecidas a partir da análise de projetos de lei que tramitaram no Congresso Nacional com propostas semelhantes, bem como de documentos disponibilizados pela Capes e pelo MEC, devido à ausência de pesquisas ou estudos que possam ampliar a produção de dados sobre essa política.

\section{O Programa de Residência Pedagógica: em que consiste a "modernização" proposta para o Pibid?}

A ideia de implantar nos cursos de licenciatura programas de residência que se aproximassem do modelo utilizado, por exemplo, nos cursos de Medicina, não é nova. Em 2007, o senador Marco Maciel propôs, por meio do Projeto de Lei n 227 , a alteração do artigo 65 da Lei no 9.394/1996, a Lei de Diretrizes e Bases da Educação Nacional (LDB), que passaria a ter o seguinte texto: "Aos professores habilitados para a docência na educação infantil e nos anos iniciais do ensino fundamental será oferecida a residência educacional, etapa ulterior de formação, com o mínimo de oitocentas horas de duração, e bolsa de estudo, na forma da lei." (BRASIL, SENADO FEDERAL, 2007a, p. 1, grifo 
nosso). No entanto, em 2011, o projeto de lei foi arquivado (BRASIL, SENADO FEDERAL, 2011).

Desde a volta das discussões a respeito do Programa de Residência Pedagógica tem gerado muito embate, que não se restringem apenas às diretrizes do programa, mas também à sua operacionalização e suas consequências para o currículo dos cursos de licenciatura.

O embate tem sido grande, pois o programa não tem angariado consenso entre os interessados. A União Nacional dos Estudantes (2017, p. 1), assim expressou seu entendimento de que a substituição do Pibid pela residência pedagógica consistia em um "[...] falso discurso de modernização, não é nada mais que a substituição da contratação de professores pela mão de obra dos estudantes de licenciatura, precarizando ainda mais nossa educação.” Ao contrário, o Pibid, segundo a instituição, "[...] é um programa com mais de 60 mil bolsas, e convênio com mais de 5 mil escolas, gerando um vínculo entre escola e universidade, fortalecendo a formação de professores e contribuindo para uma formação prática dos estudantes de licenciatura." (UNIÃO NACIONAL DOS ESTUDANTES, 2017, p. 1).

Mas, quais seriam as principais diferenças entre o Pibid e o Programa de Residência Pedagógica?

O Programa foi instituído por meio da Portaria $n^{\circ} 38$, de 28 de fevereiro de 2018, que, em seu artigo $2^{\circ}$, apresenta como objetivos do Programa de Residência Pedagógica:

Art. $2^{\circ}$ São objetivos do Programa de Residência Pedagógica:

I. Aperfeiçoar a formação dos discentes dos cursos de licenciatura, por meio do desenvolvimento de projetos que fortaleçam o campo da prática e que conduzam o licenciando a exercitar de forma ativa a relação entre teoria e prática profissional docente, utilizando coleta de dados e diagnóstico sobre o ensino e a aprendizagem escolar, entre outras didáticas e metodologias;

II. Induzir a reformulação do estágio supervisionado nos cursos de licenciatura, tendo por base a experiência da residência pedagógica;

III. Fortalecer, ampliar e consolidar a relação entre a IES e a escola, promovendo sinergia entre a entidade que forma e aquelas que receberão os egressos das licenciaturas, além de estimular o protagonismo das redes de ensino na formação de professores; e 
Reorganização Curricular da disciplina de Estágio:

Em questão o Pibid e a Residência Pedagógica

IV. Promover a adequação dos currículos e das propostas pedagógicas dos cursos de formação inicial de professores da educação básica às orientações da Base Nacional Comum Curricular (BNCC). (BRASIL, CAPES, 2018c, p. 2, grifo nosso).

Destacamos que, dentre os quatro objetivos apresentados, dois fazem referência à "reformulação" e "adequação" do currículo das licenciaturas, e dois a uma formação voltada para a prática, em que o acadêmico "exercite" a relação entre teoria e prática profissional docente, tendo as redes de ensino como protagonistas dessa formação. Não se encontra no texto da Portaria, assim como havia no Pibid, alguma menção à valorização da carreira do magistério ou contribuição para a permanência e conclusão dos acadêmicos no curso.

A ênfase na prática e a indicação de que as orientações da Base Nacional Comum Curricular (BNCC) devem balizar a "adequação" dos currículos dos cursos de formação inicial de professores sinalizam um movimento de priorização dos conteúdos escolares e metodologias previstas pelo MEC, em detrimento de uma formação teórica que possa permitir que os licenciandos tenham condições, inclusive, de questionar as metodologias e os currículos implantados nas redes de ensino.

Apple (2006), destaca que o currículo, como pode ser observado no caso da Base Nacional Comum Curricular (BNCC), não se trata simplesmente de um documento neutro proveniente das instituições de ensino, mas de um documento que reflete a complexidade das relações sociais de um determinado momento histórico. Entendemos que enquanto as ações do Pibid estavam voltadas mais especificamente para a formação dos docentes, principalmente até 2014, as do Programa de Residência Pedagógica voltamse de forma mais enfática para os resultados que os acadêmicos podem conseguir na aprendizagem dos alunos da educação básica, ou seja, na melhoria dos índices de qualidade medidos por avaliações externas.

Outra diferença entre os dois programas é que a Residência Pedagógica indica a possibilidade de aproveitamento das horas para efeito de contabilização da carga horária da disciplina de Estágio, o que não ocorria no Pibid, conforme já mencionado.

No parágrafo $7^{\circ}$ da Instrução Normativa $n^{\circ}$ 11/UFMS, de 8 de maio de 2019, por exemplo, indica-se que "A carga horária total de 440 horas da Residência Pedagógica será reconhecida para o cumprimento do estágio obrigatório". (UNIVERSIDADE FEDERAL DE MATO GROSSO DO SUL, 2019, p. 2). Isso significa que o acadêmico 
que participa do Pibid acrescenta essas experiências à sua formação, sem deixar de realizar as 408 horas obrigatórias do estágio supervisionado.

Outro fator que consideramos ser divergente entre o Pibid e o Programa de Residência Pedagógica consiste na forma em que é realizada a avaliação do desempenho dos bolsistas. No Pibid, essa avaliação é feita pelo Coordenador de Área, docente das instituições de ensino superior, por meio dos relatórios produzidos pelos acadêmicos e diante do acompanhamento se houve ampliação do seu conhecimento sobre a área especificamente abordada em cada subprojeto. Dentre as atribuições do Professor Supervisor, não se encontra alguma que indique que ele tenha corresponsabilidade na avaliação da aprendizagem dos acadêmicos, apenas no que se refere a: "controlar a frequência dos discentes, repassando essas informações ao coordenador de área; [...] enviar ao coordenador de área quaisquer relatórios e documentos de acompanhamento das atividades dos discentes sob sua supervisão, sempre que solicitado;" (BRASIL, CAPES, 2018d, p. 11).

No Programa de Residência Pedagógica, o residente é avaliado tanto pelo Docente Orientador (professor da IES), que deve "avaliar periodicamente o residente e emitir, em conjunto, com o preceptor, relatório de desempenho; cancelamento ou suspensão da bolsa do residente, quando houver;", quanto pelo Preceptor (professor da instituição escolar), que tem conjuntamente a atribuição de "avaliar periodicamente o residente e emitir relatório de desempenho;" (BRASIL, CAPES, 2018d, p. 9-10). Essa avaliação se dá tanto em função da assiduidade como da execução do Plano de Atividades, que, segundo a Portaria, deve ser desenvolvido "com assiduidade e de forma acadêmica, profissional e ética"; (BRASIL, CAPES, 2018d, p. 10, grifo nosso).

O Plano de Atividades, segundo a Portaria 175/2018, deve ser elaborado pelo discente em conjunto com o Docente Orientador, Preceptor e outros profissionais da escola envolvidos nas questões pedagógicas.

O Edital n $n^{0} 7 / 2018$ indica que essa elaboração deve levar em consideração os "princípios da iniciação à docência", assim elencados:

I. o desenvolvimento de atividades em níveis crescentes de complexidade em direção à autonomia do aluno em formação;

II. valorização do trabalho coletivo e interdisciplinar;

III. intencionalidade pedagógica clara para o processo de ensino-aprendizagem dos objetos de conhecimento da Base Nacional Comum Curricular; 
Reorganização Curricular da disciplina de Estágio:

Em questão o Pibid e a Residência Pedagógica

IV. estímulo à inovação, à ética profissional, à criatividade, à inventividade e à interação dos pares; e

V. aperfeiçoamento das habilidades de leitura, de escrita e de fala do licenciando. (BRASIL, CAPES, 2018d, p. 7).

Destacamos nesse excerto a intencionalidade de articular a formação e atuação dos residentes à Base Nacional Comum Curricular (BNCC), o que, de acordo com o que já problematizamos nesse texto, pode contribuir para conformar os licenciandos à visão de educação, homem, sociedade, escola, ensino e aprendizagem defendida por meio das escolhas arbitrárias e não neutras dos formuladores do currículo oficial.

\section{Considerações finais}

Desde o seu lançamento, o Pibid tem provocado discussões sobre a necessidade de mudanças no currículo das licenciaturas, sobretudo na disciplina de Estágio Supervisionado. De fato, entre seus efeitos, a Fundação Carlos Chagas (2014), após uma pesquisa nacional entre os participantes do programa no período de 2009 a 2013, indica que o Pibid tornou-se um '"provocador', 'perturbador', na expressão usada no depoimento - 'tensionador', no âmbito das rotinas estabelecidas no cotidiano das licenciaturas." (FUNDAÇÃO CARLOS CHAGAS, 2014, p. 30).

O estágio faz parte do currículo dos cursos de licenciatura e refere-se ao período em que o acadêmico realizam na escola atividades de observação, regência ou gestão. Sua reestruturação, como componente curricular das licenciaturas, envolve primeiramente a discussão sobre o lugar do Estágio Curricular Supervisionado na formação docente.

A partir da análise dos documentos oficiais sobre o Programa de Residência Pedagógica, acreditamos que sua proposta para substituir o Estágio Supervisionado não é coerente, uma vez que a ênfase do Programa parece ser exatamente a instrumentalização técnica e didático-pedagógica, o "saber fazer", avaliado a partir da adequação de condutas e dos resultados esperados com a aplicação do Plano de Atividades.

Nesse sentido, a forma como foi estruturado o Programa de Residência Pedagógica, apesar da indicação que visa "à autonomia do aluno em formação", por meio do "desenvolvimento de atividades em níveis crescentes de complexidade" (BRASIL, CAPES, 2018b, p. 7), direciona-se para o que Contreras (2002, p. 194) denomina de "coisificação" dos valores e pretensões educativas, que leva não à autonomia, mas à 
dependência externa por meio da regulamentação e do controle da prática docente, medidos por meio da aferição de resultados.

Dessarte, o Programa de Residência Pedagógica ora mostra uma visão pautada no modelo de racionalidade técnica, no qual, de acordo com Diniz-Pereira (2014, p. 36) "[...] o professor é visto como um técnico, um especialista que rigorosamente põe em prática as regras científicas e/ou pedagógicas", ora no modelo de racionalidade prática, que prioriza um saber-fazer "[...] rotineiro, naturalizado e reprodutivo de relações e práticas, impedindo que o professor e sua docência possam se desenvolver e se transformar continuamente." (FIORENTINI; CRECCI, 2016, p. 511).

A superação desses modelos deveria ser o cerne das propostas de reestruturação curricular da disciplina de Estágio Supervisionado. O modelo inicial do Pibid, nessa perspectiva, trouxe ao debate exatamente aquilo que tem sido alvo de críticas nos cursos de licenciatura: é preciso não somente promover o contato dos acadêmicos com as teorias pedagógicas e com o campo de atuação, ou seja, realizar a articulação entre teoria e prática, mas, principalmente, problematizar tanto as metodologias de ensino encontradas nesse campo como as teorias que as têm embasado.

Nessa perspectiva, antes, durante e depois do período em que fica imerso na escola o acadêmico necessita ter contato com conhecimentos teóricos que propiciem uma visão crítica e questionadora do status quo, não somente respondendo de forma conformadora e reprodutivista ao que o currículo oficial prescreve.

\section{Referências}

AGÊNCIA BRASIL (EBC). Programa de bolsas de iniciação à docência pode sofrer cortes em 2016, diz Capes. In: AGÊNCIA BRASIL (EBC). Notícias: Educação. 2015. Disponível em: <http://agenciabrasil.ebc.com.br/educacao/noticia/2015-10/capes-vepossibilidade-de-pibid-sofrer-cortes-de-orcamento-em-2016>. Acesso em: 28 de ago. 2016.

ADRIÃO, Theresa; PERONI, Vera. Consequências da atuação do Instituto Ayrton Senna para a gestão da educação pública: observações sobre 10 estudos de caso. Práxis Educativa, Ponta Grossa, v.6, n.1, p. 45-53 , jan.-jun. 2011.

ALMEIDA, Patrícia Albieri de; TARTUCE, Gisela Lobo B. P.; NUNES, Marina Muniz Rossa. Quais as razões para a baixa atratividade da docência por alunos do Ensino Médio?.Psicologia Ensino \& Formação, Brasília, v. 5, n. 2, p. 103-121, 2014. 
Reorganização Curricular da disciplina de Estágio:

Em questão o Pibid e a Residência Pedagógica

ANDRÉ, Marli. Políticas e programas de apoio aos professores iniciantes no Brasil. Cadernos de Pesquisa, São Paulo, v.42, n.145, p. 112-129, 2012.

APPLE, Michael. Ideologia e Currículo. 3. ed. Porto Alegre: Artmed, 2006.

BOURDIEU, Pierre. Esboço de auto-análise. Tradução Sérgio Miceli. São Paulo: Companhia das Letras, 2005.

BRASIL. Lei ${ }^{\circ}$ 9.394, de 20 de dezembro 1996. Estabelece as diretrizes e bases da educação nacional. Diário Oficial da União, Brasília, 1996.

BRASIL. Plano Nacional de Educação 2014-2024: Lei no 13.005, de 25 de junho de 2014, que aprova o Plano Nacional de Educação (PNE) e dá outras providências. Brasília: Câmara dos Deputados, Edições Câmara, 2014. (Série legislação; n. 125).

BRASIL. Projeto de Lei 7552. Acrescenta parágrafo único ao art. 65 da Lei no 9.394, de 20 de dezembro de 1996 (Lei de Diretrizes e Bases da Educação Nacional), para instituir residência pedagógica para os professores da educação básica. Brasilia, DF, CÂMARA DOS DEPUTADOS. 2014. Disponível em https://www.camara.leg.br/proposicoesWeb/ fichadetramitacao?idProposicao=615367. Acesso em 23 maio 2019.

BRASIL. Parecer da Comissão de Educação. Relatório sobre o PL 7552/2014, que propõe alteração do artigo 65 da Lei de Diretrizes e Bases. Brasília, DF, CÂMARA DOS DEPUTADOS. 2014. Disponível em https://www.camara.leg.br/ proposicoesWeb/fichadetramitacao?idProposicao=615367. Acesso em 23 maio 2019.

BRASIL. CAPES. Portaria normativa $n^{o} 38$, de 12 de dezembro de 2007. Dispõe sobre o Programa de Bolsa Institucional de Iniciação à Docência - PIBID. Brasília: Capes, 2007a. Disponível em: https://www.capes.gov.br/educacao-basica/capespibid/ documentos-pibid. Acesso em 23 maio de 2019.

BRASIL. CAPES. Edital MEC/CAPES/FNDE. Seleção pública de propostas de projetos de iniciação à docência voltados ao Programa Institucional de Iniciação à Docência Pibid. Diário Oficial da União, Brasília, 2007b.

BRASIL. CAPES. Edital Capes/DEB $n^{\circ}$ 02/2009 - Pibid. Torna público que receberá das Instituições Públicas de Educação Superior (IPES), federais e estaduais, propostas contendo projetos de iniciação à docência. Brasília: Capes, 2009. Disponível em: https://www.capes.gov.br/educacao-basica/capespibid/documentos-pibid. Acesso em 23 maio de 2019.

BRASIL. CAPES. Edital Capes n $n^{\circ} 011 / 2012$. Torna público que receberá das Instituições Públicas de Educação Superior (IPES) propostas contendo projetos de iniciação à docência. Brasília: Capes, 2012a. Disponível em: https://www.capes.gov.br/educacaobasica/ capespibid/documentos-pibid. Acesso em 23 maio de 2019. 
BRASIL. CAPES. Modelo de Termo de Compromisso do Bolsista de Iniciação à Docência. Brasília: Capes, 2012b. Disponível em: https://www.capes.gov.br/educacaobasica/ capespibid/ documentos-pibid. Acesso em 23 maio 2019.

BRASIL. CAPES. Edital $n^{\circ}$ 061/2013. Torna público que receberá das Instituições Públicas de Educação Superior (IPES) propostas contendo projetos de iniciação à docência. Brasília: Capes, 2013a. Disponível em: https://www.capes.gov.br/educacaobasica/capespibid/documentos-pibid. Acesso em 23 maio de 2019.

BRASIL. CAPES. Portaria $n^{o}$ 96, de 18 de julho de 2013. Aprova o Regulamento do Programa Institucional de Bolsa de Iniciação à Docência. Brasília: Capes, 2013b. Disponível em: https://www.capes.gov.br/educacao-basica/capespibid/documentospibid. Acesso em 23 maio de 2019.

BRASIL. CAPES. Diretoria de Formação de Professores da Educação Básica (DEB). Relatório de gestão Pibid: 2009-2013. Brasília: Capes, 2013c.

BRASIL. CAPES. Ofício Circular $n^{o}$ 2/2016-CGV/DEB/CAPES. Informativo sobre prorrogação de bolsas do Pibid. Brasília: Capes, 2016a. Disponível em: http://www.fai.com.br/portal/_arquivos/_itens_home/d182a0a6f5053c853c453e0fa9d12 328 Acesso em 21 abr. 2016.

BRASIL. CAPES. Portaria n. 46, de 11 de abril de 2016. Aprova o Regulamento do Programa Institucional de Bolsa de Iniciação à Docência - Pibid. Brasília: Capes, 2016b. Disponível em: https://www.capes.gov.br/educacao-basica/capespibid/documentospibid. Acesso em 23 maio de 2019.

BRASIL. CAPES. Portaria $n^{\circ} 84$, de 14 de junho de 2016. Revoga a Portaria $n^{\circ} 46$, de 11 de abril de 2016, que aprovava o Regulamento do Programa Institucional de Bolsa de Iniciação à Docência - PIBID. Brasília: Capes, 2016c. Disponível em: https://www.capes.gov.br/educacao-basica/capespibid/documentos-pibid. Acesso em 23 maio de 2019.

BRASIL. CAPES. Capes revoga Portaria referente ao regulamento do Pibid. Sala de Imprensa: Notícias, 15 de junho de 2016. Brasília: Capes, 2016b. Disponível em: http://www.capes.gov.br/component/content/article/36-salaimprensa/noticias/7946capes-revoga-portaria-referente-ao-regulamento-do-pibid. Acesso em 12 ago 2016.

BRASIL. CAPES. Portaria $n^{\circ} 120$, de 22 de julho de 2016. Dá nova redação à Portaria $\mathrm{n}^{\circ}$ 84, de 14 de junho de 2016. Brasília: Capes, 2016e. Disponível em: https://www.capes.gov.br/educacao-basica/capespibid/documentos-pibid. Acesso em 23 maio de 2019.

BRASIL. CAPES. A cidade de São Paulo será piloto do Programa de Residência Pedagógica. Sala de Imprensa: Notícias. Brasília: Capes, 2017a. Disponível em: http://www.capes.gov.br/sala-de-imprensa/noticias/8633-a-cidade-de-sao-paulo-serapiloto-do-programa-de-residencia-pedagogica. Acesso em 28 dez. 2017. 
Reorganização Curricular da disciplina de Estágio:

Em questão o Pibid e a Residência Pedagógica

BRASIL. CAPES. Residência pedagógica quer universalizar a iniciação à docência. Sala de Imprensa: Notícias. Brasília: Capes, 2017b. Disponível em: https://www.capes.gov.br/sala-de-imprensa/noticias/8684-residencia-pedagogica-queruniversalizar-a-iniciacao-a-docencia. Acesso em 28 dez. 2017.

BRASIL. CAPES. Portaria $n^{\circ} 45$, de 12 de março de 2018. Dispõe sobre a concessão de bolsas e o regime de colaboração no Programa de Residência Pedagógica e no Programa Institucional de Bolsa de Iniciação à Docência (Pibid). Brasília: Capes, 2018a. Disponível em: https://www.capes.gov.br/educacao-basica/capespibid/documentos-pibid. Acesso em 23 maio de 2019.

BRASIL. CAPES. Portaria $n^{\circ} 175$, de 7 de agosto de 2018. Altera o Anexo I da Portaria $\mathrm{n}^{\circ} 45$, de 12 de março de 2018, que regulamenta o regime de bolsas e colaboração. Brasília: Capes, 2018b. Disponível em: https://www.capes.gov.br. Acesso em 23 maio de 2019.

BRASIL. CAPES. Portaria $n^{\circ} 38$, de 28 de fevereiro de 2018. Institui o Programa de Residência Pedagógica. Brasília: Capes, 2018c. Disponível em: https://www.capes.gov.br. Acesso em 23 maio de 2019.

BRASIL. CAPES. Edital $n^{o}$ 7/2018. Brasília: Capes, 2018d. Disponível em: https://www.capes.gov.br. Acesso em 23 maio de 2019.

BRASIL. CAPES. Catálogo de Teses e Dissertações. Brasília: Capes, 2019. Disponível em: https://catalogodeteses.capes.gov.br/catalogo-teses/\#!/. Acesso em 24 maio de 2019.

BRASIL MINISTÉRIO DA EDUCAÇÃO (MEC). MEC lança política nacional de Formação de professores com 80 mil vagas para residência pedagógica em 2018. 2017. Disponível em: <http://portal.mec.gov.br/ultimas-noticias/211-218175739/55921-meclanca-politica-nacional-de-formacao-de-professores-com-80-mil-vagas-para-residenciapedagogica-em-2018>. Acesso em: 28 dez. 2017.

BRASIL SENADO FEDERAL. Projeto de Lei $\mathrm{n}^{\circ}$ 227, de maio de 2007. Acrescenta dispositivos à Lei $\mathrm{n}^{\circ}$ 9.394, de 20 de dezembro de 1996, para instituir a residência educacional a professores da educação básica. Autor: senador Marco Maciel. In: Diário do Senado Federal, Brasília, n. 61, p. 13515-13516, 5 maio de 2007a.

BRASIL SENADO FEDERAL. Parecer da Comissão de Educação, em decisão terminativa, sobre o Projeto de Lei do Senado (PLS) $n^{\circ} 227$, de 2007, que acrescenta dispositivos à Lei $n^{\circ}$ 9.394, de 20 de dezembro de 1996, para instituir a residência educacional a professores da educação básica. Brasília, SENADO FEDERAL, 2007b. Disponível em: https://www25.senado.leg.br/web/atividade/materias/-/materia/80855. Acesso em 23 maio de 2019.

BRASIL SENADO FEDERAL. Projetos de Lei do Senado (PLS): Status: arquivados ao final da legislatura. In: Diário do Senado Federal, Brasília, n. 213-C (Suplemento), p. 20-90, 24 jan. 2011. 
BRASIL SENADO FEDERAL. Projeto de Lei $n^{\circ} 284$, de 2012. Altera a Lei $\mathrm{n}^{\circ}$ 9.394, de 20 de dezembro de 1996, que estabelece as diretrizes e bases da educação nacional, para instituir a residência pedagógica para os professores da educação básica. Brasília, SENADO FEDERAL. 2012. Disponível em: https://www25.senado.leg.br/web/ atividade/sessao-plenaria. Acesso em 23 maio de 2019.

BRASIL SENADO FEDERAL. Projeto de Lei $n^{\circ}$ 5054, de 20 de abril de 2016. Altera a Lei no 9.394, de 20 de dezembro de 1996 (Lei de Diretrizes e Bases da Educação Nacional), para dispor sobre a residência docente na educação básica. Brasília, SENADO FEDERAL. 2016. Disponível em: https://www25.senado.leg.br/web/atividade/sessaoplenaria. Acesso em 23 maio de 2019.

CONTRERAS, José. Autonomia de professores. São Paulo: Cortez, 2002.

COSTA, Luciana Laureano; FONTOURA Helena Amaral. Residência pedagógica: criando caminhos para o desenvolvimento profissional docente. Revista @ mbienteeducação, São Paulo, v. 9, n. 2, p. 161-177, jul/dez, 2015.

CRUZ, Tânia Mara; FERNANDES, Fabrícia Machado; MENGER, Amanda. As relações de gênero na escolha da profissão do magistério no município de Tubarão-SC. Poiésis, Tubarão, Número Especial, p. 48 - 77, 2012.

DINIZ-PEREIRA, Júlio Emilio. Da racionalidade técnica à racionalidade crítica: formação docente e transformação social. Perspectivas em Diálogo: Revista de Educação e Sociedade, Naviraí, v.01, n.01, p. 34-42, jan-jun.2014.

FIORENTINI, Dario; CRECCI, Vanessa. Interlocuções com Marilyn Cochran-Smith sobre aprendizagem e pesquisa do professor em comunidades investigativas. Revista Brasileira de Educação, Rio de Janeiro, v. 21, n. 65, p. 505-524, Jun.2016.

FÓRUM NACIONAL DOS COORDENADORES INSTITUCIONAIS DO PIBID. Carta do ForPibid: contra a opressão e pela coragem de formar professores. 2016. Disponível em: <https://www.prograd.ufg.br/up/90/o/CARTA_DO_FORPIBID.pdf>. Acesso em: 28 de ago. 2016.

FÓRUM NACIONAL DOS COORDENADORES INSTITUCIONAIS DO PIBID. Informe ForPIBID $n^{o}$ 06-2017: Às ruas, já! 2017. Disponível em: http://www.cdn.ueg.br/source/pibid/noticias/34001/informe_072017_forpibid_1910201 7.pdf. acesso em 28 dez. 2017.

FUNDAÇÃO CARLOS CHAGAS. Um estudo avaliativo do Programa de Bolsas de Iniciação à Docência (Pibid). Textos FCC, São Paulo, v. 41, p. 1-120, set. 2014.

GATTI, Bernadete et al. Relatório Final: A atratividade da carreira docente no Brasil. São Paulo: Fundação Vítor Cívita, 2009.

GIOVANNI, Luciana Maria; MARIN, Alda Junqueira. (Org.) Professores iniciantes: diferentes necessidades em diferentes contextos. São Paulo: Junqueira \& Marin, 2014. 
Reorganização Curricular da disciplina de Estágio:

Em questão o Pibid e a Residência Pedagógica

GOODSON, Ivor. A Construção Social do Currículo. Lisboa: EDUCA, 1997.

GUIMARÃES, Jorge Almeida. Apresentação. In: FUNDAÇÃO CARLOS CHAGAS. Um estudo avaliativo do Programa Institucional de Bolsa de Iniciação à Docência (Pibid). Bernardete A. Gatti; Marli E. D. A. André; Nelson A. S. Gimenes; Laurizete Ferragut, pesquisadores. São Paulo: FCC/SEP, 2014.

MARCELO GARCIA, Carlos. El professorado principiante: inserción a la docência. Barcelona: Edições Octaedro, 2009.

MARQUES, Nelagley. Quem quer ser professor? Campo Grande: SED/MS, 2018. (Série: Estudos sobre a atratividade da carreira docente, v.1).

SÃO PAULO (Estado). Decreto $n^{\circ} 57.978$ de 18 de abril de 2012. Institui o Programa Residência Educacional, no âmbito da Secretaria da Educação, e dá providências correlatas. Diário Oficial do Estado de São Paulo, São Paulo, seção 1, p. 1, 19 de abr. 2012. Disponível em: https://www.al.sp.gov.br/repositorio/legislacao/decreto/2012/ decreto-57978-18.04.2012.html. Acesso em 23 de maio de 2019.

SÃO PAULO (Estado). Decreto $n^{\circ} 59.150$, de 3 de maio de 2013. Dispõe sobre o Programa Residência Educacional, instituído pelo Decreto $\mathrm{n}^{\circ} 57.978$, de 18 de abril de 2012. Diário Oficial do Estado de São Paulo, São Paulo, v. 123, n. 83, p. 1, 4 de maio de 2012. Disponível em: https://www.imprensaoficial.com.br/Certificacao/ GatewayCertificaPDF.aspx?notarizacaoID=b3b969d9-0bcd-467a-a641-eda91d8d7dd8. Acesso em 23 de maio de 2019.

SOUSA, Sandra Novais. O Pibid e a formação de professores de química: modelagem, experiências e inovação. In: SILVA, Fabrício Oliveira da; RIOS, Jane Adriana Vasconcelos Pacheco. (Org.) Iniciação á à docência na educação básica: experiências formativas no Pibid. Salvador: EDUNEB, 2019.

UNIÃO NACIONAL DOS ESTUDANTES (UNE). \#FicaPIBID essa luta nos UNE: confira nota da União Nacional dos Estudantes. In: UNE. Notícias. São Paulo, 31 de outubro de 2017. Disponível em: <http://www.une.org.br/noticias/ficapibid-essa-lutanos-une-confira-nota-da-uniao-nacional-dos-estudantes/>. Acesso em: 23 maio 2019.

UNIVERSIDADE FEDERAL DE MATO GROSSO DO SUL (UFMS). Instrução Normativa $\mathrm{n}^{\circ} 11$, de 8 de maio de 2019. Estabelece as normas para o reconhecimento do Programa de Residência Pedagógica para efeito de cumprimento do estágio obrigatório no âmbito da Universidade Federal de Mato Grosso do Sul. In: UFMS, Boletim Oficial. 2019. Disponível em: https://boletimoficial.ufms.br/. Acesso em 23 maio 2019. 
*Cristiane Ribeiro Cabral Rocha é doutoranda em Educação (UFMS), mestra em Educação (UEMS), Pedagoga (UEMS), professora substituta (UEMS) e da Rede Municipal de Ensino de Campo Grande, MS, membro do Grupo de Estudo e Pesquisa em Antropologia e sociologia da Educação (Gepase) e do Grupo de estudo e pesquisa em Narrativas Formativas (Gepenaf).

E-mail: Criscabralrocha@yahoo.com.br

Orcid: https://orcid.org/0000-0001-8321-3906

** Jacira Helena do Valle Pereira Assis é graduada em Pedagogia (UFMS), mestra em Educação (UFMS) e doutora em Educação (USP), professora titular da Universidade Federal de Mato Grosso do Sul, atua no quadro permanente do Programa de Pós-graduação em Educação. Líder do Grupo de Estudo e Pesquisa em Antropologia e sociologia da Educação (Gepase).

E-mail: jacira.pereira@ufms.br

Orcid : http://orcid.org/0000-0002-4539-6462

Sandra Novais Sousa é doutora em Educação (UFMS), mestra em Educação (UEMS), pedagoga (UNIFIMES), professora adjunta da Universidade Federal de Mato Grosso do Sul, atuando no curso de Pedagogia e no Programa de Pós-Graduação em Educação. Líder do Grupo de Estudo e Pesquisas em Narrativas Formativas (Gepenaf).

E-mail: sandra.novais@ufms.br.

Orcid: http://orcid.org/0000-0002-5965-1954 